\title{
Het donkere licht en Kinderen van ons volk van Antoon Coolen in het Tsjechisch. \\ Vertaling of adaptatie?
}

\section{Het donkere licht and Kinderen van ons volk by Antoon Coolen in Czech. \\ Translation or adaptation?}

Veronika Horáčková

\begin{abstract}
This paper presents a part of the author's doctoral thesis concerning the Czech reception of Dutch literature in the first half of the twentieth century. It examines the Czech translations of Kinderen van ons volk and Het donkere licht written by Antoon Coolen and their reception in Czech newspapers and magazines. The aim is to provide an answer to the questions of how the translations were received at the time and whether these value-judgements agree with the current perception of the quality of the translators' work.
\end{abstract}

\section{Keywords}

Antoon Coolen; Dutch literature; Czech translation; Czech reception of Dutch literature 


\section{Inleiding, onderzoeksvragen en methodologie}

In deze bijdrage presenteer ik een deel van mijn proefschrift dat zich bezighoudt met de receptie van de Nederlandse en Vlaamse literatuur in de eerste helft van de twintigste eeuw in Tsjechië. Ik richt me in het bijzonder op de Nederlandstalige plattelandsliteratuur die in die periode in Tsjechië heel populair was, wat blijkt uit het aantal vertalingen en de aandacht ervoor in de journalistieke kritiek.

In deze bijdrage wil ik nagaan hoe de Tsjechische vertalingen van twee werken van Antoon Coolen werden ontvangen, namelijk Kinderen van ons volk en Het donkere licht. Daarbij probeer ik een antwoord op de volgende vragen te vinden: Wat werd er in de toenmalige Tsjechische kranten en tijdschriften over deze twee romans geschreven? Werd er iets over de kwaliteit van de vertalingen gezegd? Corresponderen de gevonden uitspraken over de kwaliteit van de vertalingen met de conclusies van huidig onderzoek?

\section{Structuur}

Wat de structuur van mijn bijdrage betreft, ga ik eerst kort op de receptie van Antoon Coolen in Tsjechië in. Daarna neem ik de receptie van de Tsjechische uitgaven van Kinderen van ons volk en Het donkere licht onder de loep. Vervolgens bespreek ik de vertalers die de twee onderzochte werken in het Tsjechisch hebben vertaald en ga ik na hoe de kwaliteit van de vertalingen in de journalistieke kritiek werd beoordeeld. Tot slot formuleer ik een aantal conclusies op basis van mijn eigen analyse van de vertalingen.

\section{Receptie van Antoon Coolen in Tsjechië}

Antoon Coolen (1897-1961) staat bekend als schrijver van streekromans. ${ }^{1}$ Hoewel hij een Nederlander was, wordt hij vaak met de Vlaamse streekroman geassocieerd. Dat is te verklaren door het feit dat zijn romans qua stijl, sfeer en thematiek op die van de vertegenwoordigers van deze stroming lijken. In een aantal Tsjechische primaire bronnen wordt hij dan ook als een Vlaamse auteur voorgesteld. Deze tendens was overigens ook op het Duitse taalgebied te zien, voornamelijk tijdens de Tweede Wereldoorlog waarin hij door het naziregime met de Vlaamse literatuur in verband werd gebracht. ${ }^{2}$

1 Hierbij moet worden opgemerkt dat de term 'streekliteratuur' in de neerlandistiek nog niet helemaal ingeburgerd is en dat de grenzen van dit begrip wat vaag zijn. In engere zin gaat het om 'literatuur die verbonden is met een bepaalde streek en uitdrukking tracht te geven aan de specifieke "identiteit" van de ruimte en de bewoners'. Zie: Geest, Dirk de - Kusters, Wiel - Sintobin, Tom - Vanfraussen, Eveline (2005): Streekliteratuur in Vlaanderen en Nederland: Een probleemstelling. In: Spiegel der Letteren 47, nr. 2, p. 93.

2 Uffelen, Herbert Van (1993): Moderne Niederländische Literatur im Deutschen Sprachraum 1830-1990. Münster: Zentrum für Niederlande-Studien, p. 294. https://www.dbnl.org/tekst/uffe003mode01_01/index. php (geraadpleegd op 21. 10. 2019). 
De Nederlandstalige streekliteratuur werd in de eerste helft van de twintigste eeuw op grote schaal naar het Tsjechisch vertaald. Aan die populariteit liggen een aantal factoren ten grondslag. Ten eerste was dit genre toen in de Tsjechische literatuur al ingeburgerd. ${ }^{3}$ Ten tweede fungeerden de streekromans tijdens de Tweede Wereldoorlog als een soort surrogaat voor de 'vijandelijke' literatuur. Mede dankzij het publiceren van Nederlandstalige boeken hoefden de uitgevers geen werken met een uitgesproken nazi-thematiek uit te geven. ${ }^{4}$

In het Tsjechisch werden in totaal tien romans van Coolen vertaald. Voor zeven vertalingen heeft Lída Faltová gezorgd, die dus als dé vertaalster van Coolen in Tsjechië kan worden bestempeld. Ze heeft de volgende werken vertaald: Kinderen van ons volk (Romance z Brabantu, 1937), Peelwerkers (Rašelinárí, 1946), De goede moordenaar (Dobrák vrah, 1939), De schoone voleinding (Koruna života, 1943), Dorp aan de rivier (Ves u řeky, 1937), De drie gebroeders (Tři bratři, 1939) en Herberg In 't Misverstand (Hospoda U nesváru, 1942). De overige drie vertalingen werden door drie verschillende vertalers gerealiseerd, namelijk Rudolf Jordán Vonka (Het donkere licht; Temné svèlo, 1942), Miroslav Drápal (Peerke den Haas; Peerke strašpytel, 1948) en Ella Kazdová (Uit het kleine rijk; Z malého královstui, 1948). Daarnaast heeft Faltová twee toneelstukken van Coolen vertaald, namelijk De vreemdeling (Cizinec; 1934) en De klokkengieter (Zvonař; 1940). Beide drama's werden in Tsjechië in de jaren veertig meermaals opgevoerd. ${ }^{5}$

Alle eerste edities van Coolens vertalingen zijn tussen 1937 en 1948 verschenen, maar sommige werden herdrukt waarbij enkele herdrukken pas in de tweede helft van de twintigste eeuw werden gepubliceerd. De vier herdrukte romans zijn Herberg In 't Misverstand, Het donkere licht, De drie gebroeders en Dorp aan de rivier.

De populariteit van Coolen in Tsjechië manifesteert zich niet alleen in het grote aantal vertalingen en herdrukken. Daarvan getuigt ook het feit dat hij in 1947 'op uitnodiging van het Verbond van Tsjechische schrijvers' naar Tsjechoslowakije is gekomen. ${ }^{6}$

3 Engelbrecht, Wilken (2015): Zlaté ostruhy, kapitán Bontekoe, modré pondělky... K obrazu nizozemské literatury v Čechách. In: Hrala, Milan (ed.): Český překlad II (1945-2004). Praha: Univerzita Karlova - Filozofická fakulta, p. 230.

Zie ook: Engelbrecht, Wilken (2014): Streekromans en het Tsjechische ruralisme. In: Werkwinkel: Journal of Low Countries and South African Studies 9, nr. 1, p. 14.

4 Engelbrecht, Wilken (2015): The Formation of a Literary Canon of Dutch and Flemish Literature in Translation. In: Engelbrechtová, Jana (ed.): Dutch-Flemish-Central European Relations. Chapters from Cultural Relations between North-West and East-Central Europe. Proceedings of the International Conference for Cultural Studies, nr. 6. Olomouc: Palacký University, p. 81.

Zie ook: Engelbrecht, Wilken (2014): Streekromans en het Tsjechische ruralisme. In: Werkwinkel: Journal of Low Countries and South African Studies 9, nr. 1, p. 24.

5 Voor zover bekend werd De vreemdeling door de volgende toneelgroepen gespeeld: Komorní divadlo in Praag (1940), Horácké divadlo in Jihlava (1941), het Tsjechische theater in Plzeň (1941), Moravské divadlo in Olomouc (1942), Beskydské divadlo in Hranice na Moravě (1944) en de amateurgroep Hanka uit Dvůr Králové (1941). De klokkengieter werd door de volgende toneelgroepen opgevoerd: het Praagse theater Na Vinohradech (jaar onbekend), Městské divadlo in Karlovy Vary (1945), het Nationaaltheater in Brno (1946), Slezské národní divadlo in Opava (1948), Hanácké divadlo in Přerov (1946) en een amateurgroep in het toenmalige Gottwaldov (1949).

6 Goedhart, Pieter J. - Henneman, Jan C. - Krijt, Kryštof - Krijt, Rebecca - Mostert, Ivo (2018): Samen op de ,laan van Europa'. Amsterdam: Uitgeverij Pegasus, p. 41.

Zie ook: O.B. (1947): Antoon Coolen o Holandsku a o sobě. In: Rovnost (28. 3. 1947), p. 6. 
De Tsjechische media hebben grote aandacht aan zijn bezoek besteed en het met nauwkeurigheid gevolgd. Bovendien zijn er enkele artikelen over zijn oeuvre verschenen, bijvoorbeeld een omvangrijke tekst van de Nederlandse journalist Wim van Heugten die exclusief voor het katholieke literaire tijdschrift Archa (Ark) werd geschreven. ${ }^{7}$ Daarnaast verschenen er in de Tsjechische kranten en tijdschriften regelmatig recensies van Coolens boeken. Coolen wordt in de onderzochte artikelen meestal als een populaire, bekwame en veel gelezen auteur beschreven. ${ }^{8}$

Ik ga vervolgens op de receptie van Kinderen van ons volk en Het donkere licht in Tsjechië in. Ik heb juist voor deze twee romans gekozen omdat ze allebei een vergelijkbare thematiek behandelen, namelijk het rurale leven op het Brabantse platteland. Beide romans werden bovendien min of meer tegelijkertijd uitgegeven, concreet in 1928 en 1929. Men kan dan ook veronderstellen dat de Tsjechische receptie van deze boeken en de toegepaste vertaalstrategieën op elkaar zullen lijken.

\section{Tsjechische receptie van Kinderen van ons volk}

Laten we beginnen met Kinderen van ons volk. De centrale figuren in dit werk zijn pastoor Vogels en de inwoners van zijn dorp, met name de timmerman Doruske Timmer en de jonge boerin Marieke. Het rustige leven op het platteland wordt onderbroken door twee dramatische gebeurtenissen - de brand van Doruskes huis en de moord die Mariekes man op zijn rivaal pleegt.

In het Tsjechisch is de roman in 1937 onder de titel Romance $z$ Brabantu verschenen wat als 'Romance uit Brabant' kan worden vertaald. Voor de vertaling heeft Lída Faltová gezorgd. Het boek werd door de uitgeverij Melantrich gepubliceerd die toen vrij veel Nederlandstalige werken uitgaf. Het is in de reeks Epika (Epiek) verschenen die zich op buitenlandse romans richtte. Op de kaft wordt vermeld dat het om een 'roman van de oude goede Vlaamse traditie' ${ }^{\prime 9}$ gaat. Het is dus meteen duidelijk dat hij tot de Vlaamse plattelandsliteratuur werd gerekend, althans door de uitgever. ${ }^{10}$

7 Heugten, Wim van (1937): O díle Antoona Coolena. In: Archa 25, nr. 4, p. 165-168.

8 Dat Coolen in Tsjechië een populaire auteur was, blijkt bovendien uit het feit dat de Tsjechoslowaakse omroep een film voorbereidde die op Dorp aan de rivier was gebaseerd. De synopsis waarin het verhaal naar Tsjechië wordt geplaatst, werd door Coolen zelf geschreven. De verfilming die voor 1948 was gepland, werd echter niet uitgevoerd. Dit ligt waarschijnlijk aan de verandering van de politieke situatie in Tsjechoslowakije. Zie: [an.] (1947): Připravují se nové české filmy. Ves u řeky. In: Č́in (5. 7. 1947), p. 8.

9 Mijn vertaling (V.H.) Ook andere vertalingen uit het Tsjechisch zijn van de auteur van dit artikel.

10 Engelbrecht (schriftelijke mededeling, 20. 10. 2019) wijst erop dat uitgeverij Melantrich zich niet in de eerste plaats richtte op streekromans. Mogelijk heeft Jan Čep (1902-1974), redacteur van de reeks Epika, een rol gespeeld bij de uitgave van Kinderen van ons volk. Hij was immers één van de voornaamste vertegenwoordigers van het Tsjechische 'ruralisme'. Přibáň, Michal (2012): Melantrich. In: Slovník české literatury po roce 1945. http://www.slovnikceskeliteratury.cz/showContent.jsp?docId=1832 (geraadpleegd op 24. 10. 2019). Zie ook: Engelbrecht, Wilken (2014): Streekromans en het Tsjechische ruralisme. In: Werkwinkel: Journal of Low Countries and South African Studies 9, nr. 1, p. 14. 
In de Tsjechische journalistieke bronnen staan een aantal vermeldingen over het boek. Het gaat grotendeels om korte teksten die het werk promoten. Daarnaast bestaan er twee bondige recensies.

De eerste recensie vindt men in een uitgave van het cultureel-maatschappelijke tijdschrift Salon uit juli 1937. Volgens de anonieme recensent gaat het om een 'vrolijk, zuiver, wijs en rustig filosofiserend boek'. Hoewel er zich op het einde een tragische gebeurtenis voltrekt, blijft het 'een hele mooie romance'. ${ }^{11}$

Een andere korte recensie vindt men in het tijdschrift Nezávislá politika (Onafhankelijke politiek) uit juni 1937. Een onbekende recensent presenteert de roman als een tegenpool van de ernstige, op politiek georiënteerde literatuur en typeert het als 'een leuk, eenvoudig boek'. ${ }^{12}$

\section{Tsjechische receptie van Het donkere licht}

Het tweede werk dat ik onder de loep neem, is Het donkere licht. Het werk beschrijft het leven van het armoedige gezin van Simon Wijnands die op het Brabantse platteland woont en als peelwerker de kost verdient. Het verhaal concentreert zich vooral op zijn oudste dochter Marieke die later in een fabriek in de stad begint te werken, door een jonge man wordt verleid en bijna sterft aan de gevolgen van een abortus. ${ }^{13}$

In het Tsjechisch werd het in 1942 onder de titel Temné světlo gepubliceerd. De vertaling werd door Rudolf Jordán Vonka gerealiseerd en werd door de uitgeverij Plzákovo nakladatelství (Plzák's uitgeverij) gepubliceerd die zich toen om politieke redenen uitsluitend in Scandinavische, Hongaarse en Nederlandstalige literatuur specialiseerde. ${ }^{14}$ Het boek is in de reeks Nesmrtelni našeho věku (Onsterfelijken van onze tijd) verschenen. Opmerkelijk is dat de omslag door de gerenommeerde surrealistische schilderes Toyen werd ontworpen. Zoals reeds vermeld, volgde er in 1946 een herdruk die bij Papikovo nakladatelstvi (Papík's uitgeverij) is verschenen.

Het kan misschien verbazen dat Vonka Het donkere licht heeft vertaald aangezien de voornaamste vertaalster van Antoon Coolen Lída Faltová was. Omdat Faltová tijdens de Tweede Wereldoorlog kampte met een ziekte, kon ze echter niet meer werken. Daarom kreeg Vonka de opdracht om deze roman te vertalen. ${ }^{15}$

11 [an.] (1937): Co nového vyšlo. Romance z Brabantu. In: Salon 16, nr. 7, p. 1 b.

12 i. (1937): Co čísti. Literatura klidu a bouří. In: Nezávislá politika 4, nr. 20, p. 5.

13 De spanning tussen stad en platteland die in deze roman tot uitdrukking komt, is trouwens typerend voor het Tsjechische ruralisme. Zie: Engelbrecht, Wilken (2014): Streekromans en het Tsjechische ruralisme. In: Werkwinkel: Journal of Low Countries and South African Studies 9, nr. 1, p. 18.

14 Engelbrecht, Wilken - Barnard, Lianne - Smolka Fruhwirtová, Lucie - Vitáčková, Martina - Brázdová-Toufarová Eva (2015): Dějiny nizozemské a vlámské literatury. Praha: Academia, p. 509. Zie ook: Zach, Aleš (2007-2019): Slovník českých nakladatelství 1849-1949. https://www.slovnik-nakladatelstvi.cz/nakladatelstvi/ plzakovo-nakladatelstvi.html (geraadpleegd op 21. 10. 2019).

15 Engelbrecht, Wilken (2019): De 'geest van Vonka' of hoe een 'slechte vertaler' de Nederlandstalige literatuur propageerde. In: Spiegel der Letteren 61, nr. 1, p. 36. 
Ook Het donkere licht werd in de toenmalige kranten en tijdschriften gepromoot. Vermoedelijk de enige recensie vindt men in Lidové noviny (De Volkskrant) uit juni 1943. Recensent Pavel Bojar laat zich nogal kritisch over de roman uit. De personages hebben volgens hem geen diepte en werden naar zijn zeggen 'omgevormd tot figuurtjes, tot schema's zonder bloed en geest'. Bojar is verder van mening dat het 'in het boek om niets meer dan om een geslaagde oppervlakkige beschrijving' gaat. Aan de andere kant geeft hij toe dat Coolens schrijfstijl fraai is en dat de vertaler probeert hem in het Tsjechisch te behouden. ${ }^{16}$

\section{Lída Faltová en Rudolf Jordán Vonka}

Om de kwaliteit van de Tsjechische vertalingen van Kinderen van ons volk en Het donkere licht te kunnen bespreken, vind ik het belangrijk om eerst kort op de vertalers daarvan in te gaan.

Lída Faltová en Rudolf Jordán Vonka waren niet de enigen die in de eerste helft van de twintigste eeuw uit het Nederlands in het Tsjechisch vertaalden. Ze waren echter wel 'de eerste [Tsjechische] vertalers die zich in het Nederlands specialiseerden'. ${ }^{17}$ Hierbij moet worden opgemerkt dat de vertalers in die tijd vaak als cultuurbemiddelaars fungeerden en hebben meebepaald welke werken er werden uitgegeven. ${ }^{18}$

Lída Faltová (1890-1944) heeft romanistiek aan de Masaryk Universiteit gestudeerd en was later werkzaam als vertaalster en journaliste. Ze vertaalde uit het Frans, Duits, Russisch en Nederlands. Ze heeft in totaal 42 Nederlandstalige boeken vertaald, dat betekent ongeveer de helft van de Nederlandse en Vlaamse boeken die in het interbellum in Tsjechoslowakije werden uitgegeven. ${ }^{19}$ Ze richtte zich vooral op commercieel succesvolle titels. Naast Coolen hield ze zich intensief bezig met vertalingen van Johan Fabricius. Verder valt er op te merken dat Faltová's vertaling van Kaas de eerste vertaling van dit boek wereldwijd was. ${ }^{20}$

Rudolf Jordán Vonka (1877-1964) was in tegenstelling tot Faltová een vertaler-amateur. Hij was leraar en later werd hij als woordvoerder van de Tsjechoslowaakse ambassade in Den Haag aangesteld. Hij kan als een 'renaissance man' worden bestempeld omdat hij zich voor verschillende wetenschappelijke vakken interesseerde. Hij vertaalde niet alleen uit het Nederlands, maar ook uit het Engels, Duits en Latijn. Hij heeft in totaal tien boeken uit het Nederlands vertaald en richtte zich vooral op het werk van

16 Bojar, Pavel (1943): Na scestí zručnosti. In: Lidové noviny (8. 6. 1943), p. 5.

17 Engelbrecht, Wilken - Barnard, Lianne - Smolka Fruhwirtová, Lucie - Vitáčková, Martina - Brázdová-Toufarová Eva (2015): Dějiny nizozemské a vlámské literatury. Praha: Academia, p. 506.

18 Smolka Fruhwirtová, Lucie (2011): Recepce nizozemské literatury v českém literárním kontextu let 19452010. Olomouc: Univerzita Palackého, p. 36-7.

19 Engelbrecht, Wilken - Barnard, Lianne - Smolka Fruhwirtová, Lucie - Vitáčková, Martina - Brázdová-Toufarová Eva (2015): Dějiny nizozemské a vlámské literatury. Praha: Academia, p. 506.

20 Engelbrecht, Wilken - Barnard, Lianne - Smolka Fruhwirtová, Lucie - Vitáčková, Martina - Brázdová-Toufarová Eva (2015): Dějiny nizozemské a vlámské literatury. Praha: Academia, p. 507. 
Felix Timmermans. Als één van zijn grootste prestaties kan de eerste Tsjechische vertaling van Max Havelaar (1947) worden genoemd.

\section{Kwaliteit van vertalingen}

In geen van de voorhanden primaire bronnen wordt de kwaliteit van de Tsjechische vertalingen van Kinderen van ons volk en Het donkere licht direct becommentarieerd. Alleen in een recensie van andere Nederlandse boeken wordt de vertaling van Kinderen van ons volk als 'pittig' bestempeld..$^{21}$ Daarom moet ik uitgaan van uitspraken die er over de overige vertalingen van Faltová en Vonka werden gedaan.

Uit de journalistieke receptie komt naar voren dat Faltová als een bekwame, keurige en zorgvuldige vertaalster werd beschouwd. Zo beschrijft recensent 'EL.' waarachter waarschijnlijk Ella Kazdová schuilt, Faltová's vertaling van De vos en zijn staart van C.J. Kelk als 'keurig, puur en foutloos'. ${ }^{22}$ Haar vertaling van De vlaschaard wordt wederom als 'werkelijk poëtisch' bestempeld. ${ }^{23}$ In een ander artikel wordt beweerd dat haar 'foutloze' vertaling van Herberg in 't misverstand 'een perfect beeld van Antoon Coolens kunst weergeeft'. ${ }^{24}$ Faltová's vriendin Ervína Benešová-Brokešová schreef bovendien dat ze altijd zorgvuldig uitkoos wat ze ging vertalen. Ze zou naar het heet geen auteur vertalen 'die ook al van afstand naar nazisme rook'. ${ }^{25}$ Faltová's neef Jiří Pospíšil voegde eraan toe dat zijn tante bij het vertalen van een niet nader gespecificeerd Nederlands boek het origineel met de Duitse, Franse en Italiaanse vertaling vergeleek om het zo goed mogelijk in het Tsjechisch om te zetten. ${ }^{26}$

Ook in hedendaagse publicaties wordt gesuggereerd dat Faltová's vertalingen kwalitatief op een hoog niveau staan. Engelbrecht constateert op basis van de vertaling van Kaas 'dat Faltová alles exact vertaalt en dat ze de stijl van Elsschot "vrij trouw weergeeft". Aan de andere kant laat ze volgens Engelbrecht soms complexe woordgroepen weg als die niet van belang zijn.'. ${ }^{27}$ Deze aanpak zou destijds waarschijnlijk in de smaak van de

21 bn (1938): Dva romány z Nizozemí. In: Lidové noviny (19. 12. 1938), p. 3.

22 [Kazdová, Ella] (1947): Kelk, C. J.: Liška zametá stopu. In: Svaz českých knihovníků: Knihovna 2, nr. 1-6, p. 161.

23 Milotová, K. (1942): Flámská romance. In: Venkov (30. 10. 1942), p. 5.

24 Milotová, K. (1942): Vášeň a zloba holandské vesnice. In: Venkov (21. 7. 1942), p. 6.

25 In: Polák, Vladimír (1985): Literární místopis okresu Blansko. Blansko: Okresní knihovna, p. 128.

Deze uitspraak die oorspronkelijk uit het boek Žila jsem naději (Ik leefde van hoop) van Benešová-Brokešová afkomstig is, dateert uit de Tweede Wereldoorlog. Zie: Brokešová, Ervína (1972): Žila jsem nadějí. Praha: Středočeské nakladatelství a knihkupectví, p. 122.

26 Polák, Vladimír (1985): Literární místopis okresu Blansko. Blansko: Okresní knihovna, p. 129. Datering van deze uitspraak is niet bekend.

27 Horáčková, Veronika (2018): Tussen vertaling en adaptatie. Een kritische analyse van vertalingen van Nederlandstalige romans in het Tsjechisch en Duits in de eerste helft van de twintigste eeuw. In: AUC Philologica 2018/4. Praha: Karolinum, p. 88.

Zie ook: Engelbrecht, Wilken (2015): Kázus Kaas - recepce děl Elsschota v češtině. In: Engelbrechtová, Jana (ed.): Sýr. Mezinárodní recepce novely Kaas. Ukázky prvního českého překladu. Olomouc: Vydavatelství Univerzity Palackého, p. 17. 
Tsjechische vertaalcritici vallen aangezien het in Tsjechië sinds midden de negentiende eeuw wenselijk was om hoge literatuur trouw te vertalen.

In tegenstelling tot Faltová zijn er vrijwel geen primaire bronnen bekend die de kwaliteit van Vonka's vertalingen becommentariëren. De enige bekende bron is een recensie van de roman Pieter Breughel waarin de recensent zich heel enthousiast over Vonka uit. Hij schrijft dat Vonka 'met zo'n toewijding en eerlijkheid te werk is gegaan die onder onze vertalers zeer zeldzaam zijn. ${ }^{28}$ Uit later onderzoek is echter naar voren gekomen dat er van eerlijkheid geen sprake kan zijn. De voornaamste Tsjechische neerlandica Olga Krijtová heeft opgemerkt dat Vonka's vertalingen vaak foutief zijn. Ze stelde bovendien vast dat hij nogal vaak toevoegingen in zijn vertalingen verwerkte. ${ }^{29}$ Engelbrecht heeft later aangestipt dat er in alle vertalingen van Vonka sprake is van toevoegingen. In de Tsjechische uitgave van Pieter Brueghel staat maar liefst $30 \%$ meer tekst dan in het origineel. ${ }^{30}$

Om die reden wordt Vonka vandaag de dag vaak genoemd als een voorbeeld van hoe het niet moet. In de Tsjechische neerlandistiek is zelfs de term 'de geest van Vonka' ingeburgerd waarmee gebrekkige vertalingen worden aangeduid. ${ }^{31}$

\section{Analyse}

Om na te gaan of de inschattingen van Engelbrecht en Krijtová (cf. supra) ook opgaan voor de door mij onderzochte vertalingen heb ik deze aan een analyse onderworpen. Ik heb allebei de vertalingen macroanalytisch, d.w.z. in hun geheel als ook microanalytisch (enkele bladzijden) onderzocht. Vanwege het korte bestek van deze bijdrage bespreek ik geen concrete voorbeelden, maar vat alleen de belangrijkste bevindingen samen.

Men kan constateren dat de Tsjechische vertaling van Kinderen van ons volk dichtbij het origineel staat. Faltová volgt de Nederlandse zinsstructuur zonder dat dit in het Tsjechisch storend klinkt. Dit vertaalprocedé stemt overeen met de toenmalige normen. Zoals reeds vermeld, moesten de vertalingen toen het origineel nauwkeurig volgen. ${ }^{32}$ Af en toe zijn er wel kleinere afwijkingen van het origineel te vinden wanneer Faltová bijvoorbeeld Nederlandse werkwoorden door Tsjechische tussenwerpsels vervangt. Som-

28 m.n. (1935): Malîr v románě. Timmermansův román o Petru Breughelovi. In: Lidové noviny (7. 1. 1935), p. 5.

29 Engelbrecht, Wilken (2019): De 'geest van Vonka' of hoe een 'slechte vertaler' de Nederlandstalige literatuur propageerde. In: Spiegel der Letteren 61, nr. 1, p. 37.

30 Engelbrecht, Wilken (2019): De 'geest van Vonka' of hoe een 'slechte vertaler' de Nederlandstalige literatuur propageerde. In: Spiegel der Letteren 61, nr. 1, p. 40.

31 Engelbrecht, Wilken (2019): De 'geest van Vonka' of hoe een 'slechte vertaler' de Nederlandstalige literatuur propageerde. In: Spiegel der Letteren 61, nr. 1, passim.

Zie ook: Bruin, Edgar de (2009): Vonkův duch v českých překladech nizozemské literatury. In: iLiteratura. cz, http://www.iliteratura.cz/Clanek/23901/vonkuv-duch-v-ceskych-prekladech-nizozemske-literatury (geraadpleegd op 24. 10. 2019).

32 Engelbrecht, Wilken (2016): De Leeuw van Vlaanderen in het Tsjechisch: waarom zo laat en waarom driemaal?. In: Internationale Neerlandistiek 54, nr. 3, p. 171. 
mige woorden en woordgroepen vertaalt ze op een vrijere manier en vaak met vaste verbindingen zodat ze natuurlijker klinken. Er kan worden vastgesteld dat Faltová vrij consequent is wat het gebruik van eigennamen, realia en andere problematische verschijnselen betreft.

De Tsjechische vertaling van Het donkere licht wijkt daarentegen in hoge mate van het origineel af. Vonka voegt hele zinnen toe die ten eerste niet met het origineel overeenkomen en ten tweede inconsequenties als gevolg hebben, vooral wat realia betreft. Vonka wilde het Tsjechische publiek kennelijk een idee geven van de Nederlandse couleur locale omdat hij Nederlandse termen vaak onvertaald laat, maar aangezien hij tegelijkertijd ook Tsjechische begrippen toevoegt (zoals de stedennamen Beroun en Těšín en namen van de bestaande rovers Babinský en Nikola Šuhaj), hanteert hij geen consequent procedé. Vonka heeft daarmee de toenmalige vertaalnormen overtreden die met de woorden van literator Pavel Eisner (1889-1958) als volgt kunnen worden samengevat: 'De basiseis bij elke vertaling van prosa, een eis waarvan we nimmer ook maar een millimeter mogen afwijken, [...] luidt eenvoudigweg: getrouw vertolken. ${ }^{.33}$ Dat Vonka de vertaalconventies in zulke mate heeft verbroken, heeft destijds waarschijnlijk niemand gemerkt.

\section{Conclusie}

De toenmalige schriftelijke media besteden veel aandacht aan Kinderen van ons volk en Het donkere licht in de vorm van advertenties, maar het aantal recensies is eerder gering. De twee recensies van Kinderen van ons volk kunnen eerder positief worden genoemd, de enige recensie van Het donkere licht uiterst negatief.

Ten tweede kan er worden geconstateerd dat er bijna niets werd gezegd over de kwaliteit van deze vertalingen. Er bestaan wel veel uitspraken over Faltová's overige vertalingen die eenstemmig worden geprezen. Uit onderzoek uitgevoerd door hedendaagse neerlandici en uit mijn eigen analyse komt duidelijk naar voren dat Faltová terecht als een goede vertaalster werd geloofd. De enthousiaste recensie naar aanleiding van Vonka's vertaling van Pieter Brueghel lijkt echter vanuit hedendaags perspectief wat overdreven. Zijn vrije vertalingen kunnen dan ook eerder als adaptaties worden bestempeld. Dat constateert ook Krijtová wanneer ze over Vonka's vertaling van Max Havelaar het volgende schrijft: 'Voor de mensen die het oorspronkelijk niet kennen is het een interessant, boeiend geschreven boek, maar het is geen Max Havelaar van Multatuli.'34

\section{Literatuurlijst:}

[an.] (1937): Co nového vyšlo. Romance z Brabantu. In: Salon 16, nr. 7, p. 1b. [an.] (1947): Připravují se nové české filmy. Ves u řeky. In: Čin (5. 7. 1947), p. 8.

33 In: Engelbrecht, Wilken (2019): De 'geest van Vonka' of hoe een 'slechte vertaler' de Nederlandstalige literatuur propageerde. In: Spiegel der Letteren 61, nr. 1, p. 27.

34 Krijtová, Olga (1985): Multatuli en het vertalen. In: Over Multatuli, nr. 14, p. 37-41. 
[Kazdová, Ella] (1947): Kelk, C. J.: Liška zametá stopu. In: Svaz českých knihovníků: Knihovna 2, nr. 1-6, p. 161.

bn (1938): Dva romány z Nizozemí. In: Lidové noviny (19. 12. 1938), p. 3.

Bojar, Pavel (1943): Na scestí zručnosti. In: Lidové noviny (8. 6. 1943), p. 5.

Brokešová, Ervína (1972): Žila jsem nadějí. Praha: Středočeské nakladatelství a knihkupectví.

Bruin, Edgar de (2009): Vonkův duch v českých překladech nizozemské literatury. In: iLiteratura. cz，http://www.iliteratura.cz/Clanek/23901/vonkuv-duch-v-ceskych-prekladech-nizozemske-literatury (geraadpleegd op 24. 10. 2019).

Engelbrecht, Wilken (2019): De 'geest van Vonka' of hoe een 'slechte vertaler' de Nederlandstalige literatuur propageerde. In: Spiegel der Letteren 61, nr. 1, p. 25-56.

Engelbrecht, Wilken (2016): De Leeuw van Vlaanderen in het Tsjechisch: waarom zo laat en waarom driemaal?. In: Internationale Neerlandistiek 54, nr. 3, p. 169-188.

Engelbrecht, Wilken (2015): The Formation of a Literary Canon of Dutch and Flemish Literature in Translation. In: Engelbrechtová, Jana (ed.): Dutch-Flemish-Central European Relations. Chapters from Cultural Relations between North-West and East-Central Europe. Proceedings of the International Conference for Cultural Studies, nr. 6. Olomouc: Palacký University, p. $70-84$.

Engelbrecht, Wilken (2015): Zlaté ostruhy, kapitán Bontekoe, modré pondělky... K obrazu nizozemské literatury v Čechách. In: Hrala, Milan (ed.): Český překlad II (1945-2004). Praha: Univerzita Karlova - Filozofická fakulta, p. 227-245.

Engelbrecht, Wilken: Kázus Kaas - recepce děl Elsschota v češtině. In: Engelbrechtová, Jana (ed.) (2015): Sýr. Mezinárodní recepce novely Kaas. Ukázky prvního českého překladu. Olomouc: Vydavatelství Univerzity Palackého, p. 11-20.

Engelbrecht, Wilken (2014): Streekromans en het Tsjechische ruralisme. In: Werkwinkel: Journal of Low Countries and South African Studies 9, nr. 1, p. 13-28.

Engelbrecht, Wilken - Barnard, Lianne - Smolka Fruhwirtová, Lucie - Vitáčková, Martina Brázdová-Toufarová Eva (2015): Dějiny nizozemské a vlámské literatury. Praha: Academia.

Geest, Dirk de - Kusters, Wiel - Sintobin, Tom - Vanfraussen, Eveline (2005): Streekliteratuur in Vlaanderen en Nederland: Een probleemstelling. In: Spiegel der Letteren 47, nr. 2, p. 89-98.

Goedhart, Pieter J. - Henneman, Jan C. - Krijt, Kryštof - Krijt, Rebecca - Mostert, Ivo (2018): Samen op de 'laan van Europa'. Amsterdam: Uitgeverij Pegasus.

Heugten, Wim Van (1937): O díle Antoona Coolena. In: Archa 25, nr. 4, p. 165-168.

Horáčková, Veronika (2018): Tussen vertaling en adaptatie. Een kritische analyse van vertalingen van Nederlandstalige romans in het Tsjechisch en Duits in de eerste helft van de twintigste eeuw. In: AUC Philologica 2018/4. Praha: Karolinum, p. 85-91.

i. (1937): Co čísti. Literatura klidu a bouří. In: Nezávislá politika, jrg. 4, nr. 20.

Krijtová, Olga (1985): Multatuli en het vertalen. In: Over Multatuli, nr. 14, p. 37-41.

m.n. (1935): Malîr v románě. Timmermansův román o Petru Breughelovi. In: Lidové noviny (7. 1. 1935), p. 5.

Milotová, K. (1942): Flámská romance. In: Venkov (30. 10. 1942), p. 5.

Milotová, K. (1942): Vášeň a zloba holandské vesnice. In: Venkov (21. 7. 1942), p. 6.

O.B. (1947): Antoon Coolen o Holandsku a o sobě. In: Rovnost (28. 3. 1947), p. 6.

Polák, Vladimír (1985): Literární místopis okresu Blansko. Blansko: Okresní knihovna.

Přibáň, Michal (2012). Melantrich. In: Slovník české literatury po roce 1945. http://www.slovnikceskeliteratury.cz/showContent.jsp?docId=1832 (geraadpleegd op 24. 10. 2019).

Smolka Fruhwirtová, Lucie (2011): Recepce nizozemské literatury v českém literárním kontextu let 1945-2010. Olomouc: Univerzita Palackého. 
Uffelen, Herbert Van (1993): Moderne Niederländische Literatur im Deutschen Sprachraum 1830-1990. Münster: Zentrum für Niederlande-Studien. https://www.dbnl.org/tekst/uffe003mode01_01/index.php (geraadpleegd op 21. 10. 2019).

Zach, Aleš (2007-2019): Slovník českých nakladatelství 1849-1949. https://www.slovnik-nakladatelstvi.cz/nakladatelstvi/plzakovo-nakladatelstvi.html (geraadpleegd op 21. 10. 2019).

Mgr. Veronika Horáčková / 399625@mail.muni.cz

Masarykova univerzita, Filozofická fakulta, Ústav germanistiky, nordistiky a nederlandistiky Arna Nováka 1, 60200 Brno, CZ 
